Kwestia ta rodzi zresztą nowe pytania o dychotomię specjalizacji i integracje $e^{35}$ i jest szerszym problemem, przed którym stoi współczesna humanistyka.

Albo bowiem środowisko naukowe polskich humanistów zaakceptuje różnicowanie się dyscyplin i subdyscyplin, co w zasadzie oznaczałoby zgodę na scjentystyczną koncepcję podziału nauk według kryteriów: specyficzny przedmiot badań, metodologia i tworzenie własnych teorii a w następstwie eksponowanie subdyscyplinarnej nspecyficznościn, albo też zgodzi się na scalanie subdyscyplin w jedną dziedzinę wiedzy, co $z$ kolei nie będzie wymagało precyzyjnego i jednoznacznego określenia przedmiotu badan, będzie aprobatą otwartości granicy dziedzinowej na przenikanie innych dyscyplin ale także będzie przyzwoleniem na eklektyzm teoretyczny i metodologiczny. $\mathrm{Ku}$ której z tych dwóch moźliwości skłania się dzisiaj profesjonalne środowisko polskich historyków wychowania?

\title{
Ewaryst Estkowski i jego kontakty z seminariami nauczycielskimi we Wroclawiu w XIX wieku
}

\section{(Z badań nad przenikaniem myśli pedagogicznej w zaborze pruskim w XIX wieku) ${ }^{1}$}

\begin{abstract}
W okresie zaboru pruskiego można było niewątpliwie zaobserwować wzajemne relacje i ewidentne wpływy pomiędzy niemiecką (pruską) i polską myślą naukową.

Pierwsza z nich miała szerokie (można powiedzieć nieograniczone wprost) możliwości rozwoju. Prusy dysponowały bowiem znacznym potencjałem naukowym, skupionym głównie w licznych uniwersytetach i innych placówkach naukowo-badawczych, i towarzystwach naukowych. Przywiązywały także znaczną wage do rozwoju nauki².

Druga zaś, polska myśl naukowa, była ograniczona w swym rozwoju pruską polityką oświatową i naukową; rozwijała się dzięki silnym jednostkom i grupom, najczęściej w miarę możliwości organizującym się $w$ różne sformalizowane zbiorowości $i$ towarzystwa.

Te wzajemne relacje $i$ wpływy są do odnotowania $w$ wielu dziedzinach ówczesnej wiedzy. Polacy z zaboru pruskiego studiowali, z braku uczelni wyższej na tym obszarze, głównie w niemieckich wyższych uczelniach.
\end{abstract}

\footnotetext{
${ }^{39}$ S. Sztobryn, Hustoria doktryn pedagogicznych - niepokoje interpretacyjne. (W;) T. Jałrnużna i I. G. Michalscy (red.L Metodologin w badaniach.... s. 63 .

'Problematyka ta obejmuje jeden z temalów badawczych podejmowanych wspólnie przez polskich i viemieckich his toryków wychowania. Jest ona niezwykle skomplikowana i trudna. Szczególne trudności w tym zakresie wynikają z syluacji Polaków w zaborze pruskim oraz faktu, iż niemiecka myśl pedagogiczna tego okresu, w szczególności normatywno-praklyczne poczynania zaborcy na płaszczyźnie m.jn oświaty w zasadniczej cześcj skierowane były przeciw Polakom j podejmowane wbrew interesom narodu polskiego. Por. m.in. J. Hellwig, Z problemow wspdlpracy polskich i niemieckich historyków wychowania. „Przegląd Zachodnj” 1985, ar 1; tenże, Fryderyk A W. Diesterweg (1790-1866). Sesja naukowa w Berlinie (29-31X.1990). .Przegled Historvczno-Osiwialowy" 1992 nI 12 .

${ }^{2}$ Por. m.jn. nowe seryjne wydawnictwo w RFN - Die Deutschen und Ihre Nation: Neue Deutschland Geschichte in sechs Bänden, a zwłaszcza rozdzial pL. Wissen ist Macht, w tomie II pt: Das ruhelose Reich. Deutschland 1866-1918. Berlin 1983 (napisany przez Michaela Stürmera, prof. Uniwersytetu w Erlangen).
} 
Te wzajemne relacje $\mathrm{i}$ wpływy są ewidentne również na gruncie nauk pedagogicznych. Zaznaczyła to już m.in. polska historiogralia z tego zakresu ${ }^{3}$.

W niniejszym opracowaniu pragniemy wyeksponować te doświadczenia, jakie na grunt polskiej teorii i praktyki pedagogicznej przeniósł wielkopolski pedagog, ojciec polskiej szkoły elementarnej, Ewaryst Estkowski (1820 - 1856), w szczególności w okresie swego pobytu we Wrocławiu w latach 1844 - 1846.

E. Estkowski w czasie swego pobytu we Wrocławiu, obok realizacji studiów wolnego słuchacza Wydziału Filozoficznego Uniwersytetu ${ }^{4}$, starał się także zapoznać z bieżącą praktyką pedagogiczną w niemieckich seminariach nauczycielskich ${ }^{5}$. Chodziło $\mathrm{z}$ jednej strony o poznanie aktualnych prądów w zakresie kształcenia nauczycieli dla szkół ludowych, z drugiej zaś - o konkretną praktykę danej szkoły, gdyż seminaria nauczycielskie w Prusach w niektórych ramach czasowych posiadały swoistą autonomię, a kierunek pracy danej szkole nadawał zwykle jej dyrektor ${ }^{6}$.

W czasach, gdy Estkowski przebywał we Wroclawiu działały w tym mieście dwa seminaria nauczycielskie: Katolickie Seminarium Nauczycielskie i Ewangelickie Seminarium Nauczycielskie ${ }^{7}$. Pierwsze z nich, założone w $1765 \mathrm{r}$, kierowane było przez niemieckiego księdza Karola Barthla i zaznaczyło się wielkimi wpływami żagańskiego opata Jana Ignacego Felbigera, drugie kierowane nieco wcześniej (do 1822 r.) przez niezwykle doświadczonego teologa i pedagoga ewangelickiego Wilhelma Harnischa ${ }^{9}$, było swoistą ostoja pruskiego pestalocyzmu, za którego centrum uważany był właśnie Wrocław („....Breslau wurde die Hauptstätte das preussischen Pestalozzianismus") ${ }^{10}$.

$\mathrm{K}$. Barthel znany był w Wielkopolsce i innych częściach zaboru pruskiego, w szczególności nauczycielom, gdyż miał wcześniejsze związki z seminarium nauczycielskim w Paradyźu, gdzie był dyrektorem.

Urodzony we Wrockawiu, studiował w tym mieście na Uniwersytecie (dawnym jezuickim Leopoldinum) filozofię, a następnie teologię katolicką, po czym przyjął święcenia kapłańskie. Po objęciu parafii w Reisse, a następnie Hartmanndorfie postanowił poświęcić się pracy pedagogicznej, w szczególności w dziedzinie nauczania religii i wychowania religijnego.

Obok spełniania niezwykle rzetelnie swojej funkcji dyrektor seminarium katolickiego udzielał się także jako kapelan w klasztorze sióstr Urszulanek we Wrocławiu oraz jako opiekun duchowy i wychowawca w zakładzie dzieci głuchych. Wyławiał także utalentowanych chłopców do studiów teologicznych i stanu kapłańskiego.

Relacjonujący historię katolickiego seminarium nauczycielskiego we Wrocławiu jeden z jego nauczycieli i późniejszy dyrektor Laurentius Marks podkreśla, iż Barthel był niezwykle zdolny, bardzo pracowity i niezwykle wymagający od siebie i od innych. Znany był we Wrocławiu ,....als tüchtiger und einflussreicher Schulmann..."11. Był autorem wielu prac pedagogicznych, znaczących

${ }^{3}$ Por. m.in. M. Krupa, Fryderyk Adolf Diesterweg i jega wplyw na poiska pedagogike XIX wieku. Wrockaw 1976 (Patrz też moja recenzja tej ksiqżki w "Przeglądzie Zachodnim” 1977, nI 2); J. Hellwig, Dzialalnośc pedagogiczna Augusta Cieszkowskiego. Poż日ń 1978; tenże, Cieszkowski. Warszawa 1979; tenże, Ewaryst Estknwsk (1820-1856) prekursor nowatorstwa pedagogicznego w Polsce. Pozngń 1984; W. Schrōder, Adolph Diesterweg. Studien zu seiner Wirkungsgeschichte in der Pödagogik des 19. und 20. Jahrhunderts. Frankfunt a Main, Berlin, München $1978 \mathrm{i}$ in.

1 Por. m.jn. F. Andrese, Aus dem Leben der Universität Breslau. Breslau 1936; tenże, Schlesische Friedrich Whhelms Universität Breslau (W:) Das Akademische Deutschland. Berlin 1930, H. Helfritz, Aus der Geschichte der Breslau Universität. Jahrbuch der Schlesischen Friedrich-Wilhelms-Unjversität 2u Breslau. VI. Wũtzburg 1961; G. Kaulmann i in. Festschrif zur Feier des 100-jährigen Bestehens der Universität Breslau 2 Bände. Breslau 1911; $j$ in.

${ }^{3}$ Por. m.jn. J. Hellwig, Ewaryst Estkowski., a 34

" K Slasierskj, Ksztalcenie nauczycieli szkd! ludnwych w Whelkim Ksiestwie Poznańskim w latach 1815 - 1914. Bydgoszcz 1967, a. $24 \mathrm{in}$.

'W. Harnisch, Die Schullehrerbildung. Für die, welche suchen. und fïr die welche sie befördern. Eisleben 1836, s. 3 i 4.

'Lexikon der Pädagogik van F. Sander. Breslau 1885, s 48 i n.; Geschichte des katholischen Schulehrer - Seminars zu Breslan Ein Beitrag zur Geschichte des katholischen Schulwesens im Schlesien. Zur Fejer des hundertjährigen Bestehens der Anstalt herausgegeben von der Direktor des Seminars Laurentius Marks. Breslau 1869. Der Er1rag ist zu einer "Jubileums-Stiftung" für ame Seminaristen bestimm \& $167 \mathrm{i}$ n.

' Ch. G. Schol, Meine Erlebnisse als Schulmann Breslau 1862, s 226 i n

${ }^{10}$ Encyklopōdisches Handbuch der Pädagogik Hrsg. von W. Rejn. 2 Auflagc, 4, Bd. Langensalza 1906, a 49.

${ }^{11}$ L. Marks, Geschichte des katholischen.-, s 167 
dla tamtego okresu, a obecnie stanowiących ważne źródło dla jego poznania. Wydał m.in. Religionsgeschichte, gdyż do wychowania religijnego przywiazywał dużą wage. W opracowaniu tym kładł jednak szczególny nacisk na metodę nauczania. Podkreślił to historiograf seminarium relacjonując, iż uczący tam nauczyciele poznali od niego (tzn. od Barthla) działalność pedagogiczną $z$ innej zupełnie strony, $z$ dużym naciskiem na metodę nauczania.

Za jedną z najważniejszych jego prac uważa się Schul-Pädagogik (Breslau 1848). „Ein schönes Denkmal seiner pādagogischen Thātigkeit hat er sich durch dieses Werk gesetzt" - pisze wspomniany L. Marks ${ }^{12}$.

Barthel opracował syntetycznie ujęte zadania seminarium, które obejmowały m.in.:

- przekonanie wychowanka o fakcie, iż przygotowuje się do pracy w szkole ludowej, glównie na wsi;

- uzyskanie przez seminarzystę znacznie szerszych horyzontów umysłowych niż jego uczeń (temu celowi miał służyć cały proces nauczania, a w szczególności nauka religii, jezzyka ojczystego, geografii, historii, teorii muzyki itp.);

- przygotowanie wychowanka do dalszej pracy samokształceniowej;

- Iozwijanie całej osobowości wychowanka;

- przekonanie wychowanka, iż podstawę edukacji stanowi wychowanie religijne;

- stwarzanie okazji starszym seminarzystom do wykazania się praktyczną działalnością społeczno-pedagogiczną.

Ze statusem seminarium i powyższymi zadaniami dyrektor Barthel zapoznawał każdego z wychowanków osobiście ${ }^{13}$.

Katolickie Seminarium Nauczycielskie we Wrocławiu było wówczas dużym zakładem i liczyło około 150 seminarzystów. Od 1843 r. korzystało z nowo otwartej szkoły ćwiczen na 150 uczniów.

Biblioteka seminarialna liczyła w tym czasie 1455 woluminów oraz 731 utworów (partytur utworów) muzycznych.

Drugie, ewangelickie, seminarium nauczycielskie we Wroclawiu realizowało w czasie pobytu Estkowskiego spuściznę po wspomnianym już pietyście W. Harnischu, który może bardziej zasłynął jako dyrektor podobnego seminarium nauczycielskiego $w$ Weissenfels ${ }^{14}$.

Urodził się w okolicach Poczdamu (Wilsnack, w 1787 r.) w skrajnie religijnej rodzinie ewangelickiej. Po odbyciu studiów na Uniwersytecie w Halle, gdzie gruntownie poznał idee pietystów, a szczególnie działalność pedagogiczną pastora Augusta Hermanna Franckego' ${ }^{15}$, został teologiem ewangelickim interesującym się szczególnie problematyką nauczania i wychowania. Miał okazję w Berlinie zostać nauczycielem w Instytucie dra Jana Ernesta Plamanna (1771 - 1834), byłego ucznia Pestalozziego z Burgdorfu. Miał tam możliwość szczegółowego zapoznania się z systemem ojca szkoły elementarnej, co wywarło znaczny wpływ na jego dalsze prace ${ }^{16}$. W Instytucie Plamanna zaprzyjaźnił się z Fryderykiem Ludwikiem Jahnem (1778 - 1852) zwanym przez Niemców „Turnvater"17. Poglądy Jahna na wychowanie fizyczne rzutowały w znacznej mierze na jego prace w seminariach nauczycielskich odnoszące się do rozwoju fizycznego młodzieży.

Kierując seminarium nauczycielskim we Wrocławiu był wielkim propagatorem pestalocyzmu i kultury fizycznej.

Zasłynął m.in. w tym czasie jako autor wielu prac pedagogicznych, a szczególnie jako wydawca Der Schulrat an der Oder ${ }^{18}$.

12 Ibjdern, \& 169.

${ }^{13}$ Das Seminar zu Weissenfels. Festschrift zur Feier seines 100-jāhrigen Bestehens gewidenet von G. Seelinger, Seminardirektor. Halle (Saale) 1894. Harnisch byl tam dyrektorem w latach 1822-1842.

14 Ibidem.

15 August Hermann Francke. $1663-1727$. Hrsg. R. Ahrbeck und B. Thaler. Halle (Sagle) 1977

16 Por. m.in. W. Russ, Geschichte der Pädagogik. Bad Neilbrunn 1965, s 10.

17 Ibidem, s. 90

18 Der Schulrat an der Oder, für Verstehen der Volksschulen, Lehrer an demselben und andere Freunde und Beforderer des Volksschulwesen. Hrsg von Daniel Krüger und von Wilhelm Harnisch. Breslau 1812 (?)-1816 (?). 
Seminarium, którym kierował zostało w 1846 r. rozwiązane przez władze pruskie jako efekt swoistej próby sił między liberałami a szczególnie ortodoksyjnym ministrem Oświecenia Janem Albertem Eichornem ${ }^{19}$.

Wpływy Jahna zaznaczały się w zrozumieniu roli i znaczenia wychowania fizycznego oraz tworzenia warunków dla jego rozwoju. Chodziło także o zmianę ukierunkowania w wykorzystaniu potegi fizycznej czlowieka nie dla demonstracji siły, ale rozwoju całej osobowości, uszlachetnienia człowieka, dania mu zadowolenia, satysfakcji, przyjemności i szczęścia. W tej kwestii Harnisch pisał m.in.: „Körperkraft ist nicht notwendigerweise mit Grobheit oder mit Raufsucht und Klopffechterei verbunden, sondern oft ein Mittel dagegen; weil der, welcher sich seiner Kraft bewusst ist, sich schāmt, gegen einen Schwächeren sie zu gebrauchen. Körpergewandtheit und Gelenkigkeit brauch nicht zu Seiltänzerei, Leibverschränkungen und Taschenspielerkünstesten zu führen"20.

Stąd też z inicjatywy Harnischa wybudowano we Wrocławiu specjalny plac do ćwiczeń fizycznych (Turnplatz), co było przysłowiowym kolcem $w$ oku (,...ein Dorn im Auge") dla przeciwników postępu w dziedzinie szeroko rozumianych procesów wychowania i dla elementów zachowawczych.

Innowacje pedagogiczne wprowadzone przez Harnischa spowodowały tym samym ostre konflikty na Śląsku, a w szczególności w środowisku wrocławskim tak dalece, że zmuszony został do wstrzymania dalszych udoskonaleń procesu nauczania i wychowania, a następnie - po licznych trudnościach - do odejścia z Wrocławia do małego miasteczka Weissenfels, gdzie objął również dyrektorstwo ewangelickiego seminarium nauczycielskiego.

Z krótkiej charakterystyki działalności obu seminariów można wnosić, że Estkowski odwiedzając je ${ }^{21}$ mial okazję do zapoznania się $\mathrm{z}$ wielu interesującymi problemami pedagogicznymi, zwłaszcza w dziedzinie kształcenia nauczycieli szkół elementarnych.

Dodać wypada, że na terenie seminariów nauczycielskich we Wrocławiu, w szczególności w murach seminarium ewangelickiego odbywały się konferencje nauczycieli (Konferenz für Volksschullehrer). Miały one m.in. charakter wymiany doświadczeń. Zbierało sie około 400 nauczycieli, by debatować nad następującymi przykładowo tematami: Die Pādagogik Herbart's und seiner Schule; Harnisch und seine Bedeutung; Die ungeteilte einklassige Volksschule; Die Raumlehre in der Volksschule; Religionsunterricht itp. ${ }^{22}$.

Odbywały się też święta nauczycieli (Lehrerfeste). Ukazywały się liczne czasopisma nauczycielskie, a m.in. Schleisische Schullehrerzeitung, Blatt des Volksschullehrer, Wochenblatt für Schulen, Der Erzieher, Pādagische Blātter für Lehrerbildung itp.

Wydano również seryjne publikacje dla nauczycieli, m.in. w ramach Neue Bibliothek für Pädagogik, Schulwesens und die Gesamte Literatur Deutschlands, Bibliothek pädagogischer Klassiker $\mathrm{i}$ in.

Dzialały stowarzyszenia nauczycielskie, a m.in. Breslauarische Schullehrerverein itp. ${ }^{23}$

Można więc wnioskować, że pobyt Estkowskiego we Wrocławiu umożliwil mu nie tylko studiowanie na tamtejszym Uniwersytecie, ale pozwolił mu także na zapoznanie się z organizacja kształcenia nauczycieli. Dostarczyło to mu głębokich przeżyć, wzbogaciło jego doświadczenia, a nawet spowodowało istotną transformację jego osobowości. Odtąd bardziej zdecydowanie będzie stawiał w swoich pracach i praktycznej działalności szczegółowe problemy pracy szkoły i nauczyciela.

W szczególności będzie kładı nacisk na metody nauczania, których można dopracować się po dobrym przygotowaniu $w$ seminarium nauczycielskim stojącym na wysokim poziomie

Por m.jn. A. Heidrich, Die Auflösung des evangelischen Schullehrerseminar zu Breslau am 29. Januar 1846

20 Encyklopädisches Handbuch., \& 29.

1) W casje, gdy Estkowski przehywal we Wrodawiu dyrektorem saminarium ewangelickiego byl pastor Gerlach. Por. G. Schalz, Meine Erlebnisse...

22 Par. G. Selinger, Das Seminar 22 Weissenfels... \& 91 i 92

${ }^{13}$ Por. min. Ch. G. Scholz, Meine Erlehnisse..., s.226 i n; R. Rissmann, Geschichte des Deutschen Lehrerverein. Lcjpzig 1906 
i kierowanym przez dyrektora o pełnej, znaczącej osobowości. Pomocą okaże się samokształcenie poprzedzone odpowiednim zorganizowaniem warsztatu pracy. Ułatwić to moga organizacja nauczycielska, czasopismo pedagogiczne, kontakty między nauczycielami, wymiana zdobytych doświadczeń.

We Wrocławiu niewątpliwie lepiej zrozumiał teoretyczne założenia i praktyczną realizację idei pietystów i pestalocystőw oraz rolę szkoły elementarnej jako jednej z głównych podstaw dalszej edukacji człowieka.

Slawomir Sztobryn

Lódź

\section{Badania nad Filozofią Pedagogii Józefa Hoene-Wrońskiego w czasopiśmiennictwie pedagogicznym w latach 1918 - 1939}

Literatura poświęcona temu równie wybitnemu co kontrowesyjnemu filozofowi $w$ badanej przestrzeni czasowej nie jest obfita, a mimo to bogatsza niż współcześnie. Spośród dziewiętnastowiecznych filozofów-pedagogów właśnie on konstruowal najbardziej hermetyczną $i$ uniwersalną wizję świata, człowieka i jego rozwoju. Wtórowali mu B. F. Trentowski, A. Cieszkowski, K. Libelt, ale żaden $z$ nich nie szedł $w$ swych koncepcjach tak daleko.

Międzywojenne czasopiśmiennictwo nawiązywało do wybitnych postaci zazwyczaj w związku $z$ jakąś określoną rocznicą Tak było i w przypadku Wrońskiego, choć jego popularność w niektórych kręgach intelektualnych była szczególna. Rozprawy powstawały krótko przed, jak i po 150 rocznicy urodzin (1928). Pisane były przez znanych filozofów (Jastrzębiec-Kozłowski), jak i pedagogów (Rowid). Wroński zainteresował także prof. literatury porównawczej na Sorbonie - Fernanda Baldenspergera oraz Franka Walsera, którego rozprawa została przełożona z języka francuskiego.

Spośród czasopism, na lamach których podejmowano badania nad filozofią wychowania Hoene-Wrońskiego, tylko właściwie jedno - Minerwa Polska - posiadało orientację historyczno-pedagogiczną. Inne, takie jak Ruch Pedagogiczny czy Miesięcznik Pedagogiczny nastawione były bardziej na najnowsze zagadnienia pedagogiczne. Jeszcze bardziej odległy od ujęć historycznych był Przeglad Wspólczesny, natomiast w ramach Sprawozdań z Czynności i Posiedzeń PAU prezentowane były prace różnych komisji - w przypadku Wrońskiego - Komisji do Badania Dziejów Filozofii w Polsce.

Dająca się dostrzec różnorodność punktów widzenia uniemożliwia odnalezienie jakiegoś wspólnego wszystkim autorom kryterium historycznego, natomiast wydaje się, że sprzyjała utwierdzeniu więzi filozofii i pedagogiki, mimo znaczącego ożywienia badań eksperymentalnych prowadzonych w oparciu o dynamicznie rozwijającą się psychologię i socjologię. Rzadko spotyka się w literaturze, szczególnie w czasopiśmiennictwie, aby każde kolejne ujęcie odznaczało się odmiennością punktu widzenia, odwoływało się do różnych momentów twórczości danego filozofa czy pedagoga. Drugim znamiennym rysem jest, odmienne niż zazwyczaj, postawienie badań biograficznych (które nota bene sq w tym przypadku rzeczywiście frapujące) na drugim miejscu a skoncentrowane są na doksografii.

Ożywienie zainteresowania Wrońskim nastąpiło po 1920 roku kiedy rozpoczęto prace translatorskie (do dziś nie ukończone) ${ }^{1}$. Jest to zaskakujące, bowiem obok Trentowskiego, był on uważany za najwybitniejszy „polski umysł filozoficzny”. Postrzegano go nawet jako rodzimego Sokratesa ale $z$ tragicznym rysem - nigdy nie wykształcił swego Platona. Jako niepospolita

${ }^{1}$ H. Rowid, Idealy wychowawcze w filozofii polskiej. „Miesięcznil Pedagogiczny” 1925, T. 34, \&. 259. 